\title{
How do Higher Education Students manage their Digital Footprints before Finding a Job?
}

\author{
Katalin Fehér \\ School of Communication, Taylor's University, Malaysia \\ katalin.feher@taylors.edu.my
}

\begin{abstract}
We have identities and we can communicate online on the internet and in social networks. The question is how we can define and manage social roles/online representations on digital platforms and in social media? "Digital identity" is in the focus in this exploratory phase of our research the aim of which has been to map how identity refers to a driver in a digital setting with digital footprints, visibility or nonvisibility, professionalism and privacy in online publicity. Our empirical research has been trying to explore this phenomenon of the digital media for online personal strategy with segmentation. The first exploratory phase focused on the students' segment prior to initial employment. We were wondering which points of decision were relevant in digital identity strategy for them and how they would replace their strategy consciously prior to employment. We had a qualitative research with semi-structured interviews. Our results show that digital identity phenomena define social roles/online strategies and representations on digital platforms and in social media. Members of the research segment have some strategies to manage their digital footprints. They would like to change their profile from "student" to that of a "professional" assuming less activity in digital context.
\end{abstract}

Keywords: Digital footprint, digital identity, network impact, reputation, visibility

\section{Introduction}

'Digital identity' for us refers to the first impressions of drivers in digital settings with digital footprints, visibility or non-visibility, professionalism and privacy. At this stage the focus is on personal and social identity (Erikson 1968; Tajfel \& Turner, 1979, 1986) based on terms of social psychology and on online media context. The goal of this paper is to present the phenomenon of digital identity observed in the first research segment. This is a research in progress and it is in its exploratory module with a desktop research and with its first qualitative phase. We were interested in points of decision/elements of digital identity strategy from our first segment. This segment involved students from various universities before finding their first job. The main question was how they managed their digital identity and how they would replace their strategy consciously prior to employment. Our qualitative research with semi-structured interviews promotes the mapping of social roles/online strategies and representations on digital platforms and in social media. We analysed the strategies observed in the research segment in order to manage digital footprints and online reputation, the control of and the organisation of forms of online visibility that, also, constitute networks' impact. We assumed they have a complex mix of skills and experiences with new technologies (Kennedy et al., 2006, 413). First we are going to focus on the research field and its importance and, also, on strategic perspectives; second, we are going to present an insight via results of our first qualitative research.

Background and relevance of "digital identity" research: As our desktop research on digital lifestyle and social networks go on, it streams online data concerning and issued by users. Users have digital identities that refer to the first impressions of drivers in digital settings with digital footprints, visibility or non-visibility, professionalism and privacy. We are digitalised and mediatised. We define our identities and our social networks in/on/via/for new media. Digital footprints are links in networks of networks. Me 2.0 (Schawbel, 2009) is self-generated and self-represented, operated and processed by interactivity based on online communities (Buss and Strauss, 2009) by professional or other sites. We have personal and social identities and we can communicate on- and offline. We are actually linked via web 2.0 platforms and online applications. The question is: "who are we in digital networks"? The World Wide Web has become a playground for us (Aaltonen et al., 2005). We learn the online network rules to control digital technology and this affects identity online (Blanchard \& Markus, 2007). A digital identity is constituted by a set of online data, 
which defines personal and social identity, or some other type (e.g. corporate or organizational identity) of identity, to be identified and distinguished. Digital identities leave digital footprints and copies of digital footprints. The main difference between real world identity and digital identity is constituted via frameworks of digital platforms, online publicity and algorithms. Social media feature this interconnectivity and interplay (Adler, Rosenfeld \& Proctor, 2010) among users. Social activity, collaboration and co-working online (Dellarocas, 2010), interactivity and content sharing result in more cases when digital identity roles meet. The well-known point is a conflict between privacy and reliable identification (Shao, 2009). Finally users need a strategy to avoid this. Social networking has also some relevance to certain psychological aspects and to motivations. Self-actualization and self-expression, for the time operating, might play an important role in these networks. "Psychological constructs such as empathy, creativity, congruence, notions of justice and selfconfidence are also likely to be related to active use" (Shao, 2009, 453). We need to study and search digital identity strategies and chains of decisions, where "decision making is a complex phenomenon which normally is deeply integrated into social life" (Allwood \& Selart, 2001: xi). We are interested in the practise, in behaviours, attitudes, strategies or in the lack of strategies in everyday life with social and personal dimensions concerning phenomena of digital identity.

Focus and empirical research questions: We are interested in this strategy of digital identity: we are focusing on real world personal strategy online in social connectivity. Digital identity phenomena have an extension these days: this is mobile identity via smart phones and other smart devices. Personal media (Aaltonen, Huuskonen \& Lehikoinen, 2005) determine the future for mixing/augmented digital identities with updated strategies. We can prepare its research with our present observations to compare later phenomena. The goal is to examine the student segment that has a complex mix of skills and experiences with new technologies - and this is happening prior to a professional lifestyle. Their online communication and decision points of digital identity belong to a student lifestyle but we assumed it was also in preparation for/expecting their professional future. Our empirical research questions are:

- How can they define social roles/online representations and their strategies on digital platforms and in social media?

- How do they behave and what goals are we following while being connected to digital networks?

- Would generation members involved in our research segment replace their strategy consciously prior to employment?

- Which points of decision points are relevant in digital identity strategy for students in higher education before their first job?

We focused on their digital embeddedness and on their attitudes online, narrowing the wider circle concept about their original category for "consumer behaviour". We examine their strategy of social identity in online networks. Our research tries to explore and identify digital identity strategies in online usage and decisions in digital environment/platforms.

\section{Methodology and research limits}

Exploratory modules employ practical qualitative methods: we need to map and collect different details and strategies in categories and types of habits. The topic implies a complex and interdisciplinary framework. The expected complex and sensitive content to be analysed was clearly part of the interview's methodology. We used guideline questions in the semi-structured interviews and in the questionnaire with 15 statements. The main points of guideline questions were:

- How do you check yourself and others on the net?

- How important is it that somebody appears on the net, or how important is it to stay invisible?

- How much time / energy do you spend on checking or controlling the presence of others? Do you have tools for this?

- How do others affect your appearance in online presentation (family members, friends, schoolmates, companies, institutions)?

- How can you operate self-control on the net?

- How do you search for information about others? And about yourself?

- Do you know rules/tools with which you can control these (privacy rules, security)? 
We would like to feature the significance of the subject, and tune in to the matter for reflection. We used Excel, Sporkforge, MAXQDA for analysis. We cleaned terms from modified grammatical structures and summarized frequencies of redundancy. We encoded larger, complex units. Finally our random sampling provided 15 interviews: 8 men and 7 women were interviewed at different universities and from bachelor and master programs, they live in capital/bigger cities or in cross-border towns, and they have various backgrounds in online activity. The present research and methodology demonstrate that we should keep our limits in mind. The sampling size was small with 15 interviews and questionnaires but it could be sufficient in qualitative research (Bauer \& Gaskell, 2007: 43), especially in a well-defined, smaller segment to map main parameters of strategies and motivations. However, this study cannot map the total of digital identity phenomena, yet it tries to explore key decisions and strategic elements of online self-presentation (Mehdizadeh, 2010) on the test segment. We assume other segments apply various strategies, the social roles and social statuses determine online communication decisions.

\section{Results}

Finally we had 15 voice recordings and in these 15 transcripts we studied the frequencies of words and shared foci. The software was auto coding and providing a code-by-list support to filter typical content elements and contexts based on focal questions. We used indicators to organise and interpret empirical research results with a feedback for focal questions. Our indicators were:

- Usage of digital tools

- $\quad$ Digital identification tools

- Roles, behaviour and goals in digital networks

- Points of decision in digital identity context

- Strategy shift consciously prior to employment

To sum up the results our interviewees are active users and they are aware of the "digital identity" phenomenon basically and they have multiple strategies to handle it. On the other hand they have many questions and uncertainty in this field and in most interviews our attention has also been drawn to the importance of the topic and students indicated/recognised during the interview that they would have to check earlier digital footprints of their own. The first indicator was informants' digital usage. Their online activities mainly consist of search, posting, e-mail sending, clicking on the "like" icon and sharing comments in online communication - word frequency indicates this in the interview corpus. Facebook is an extremely frequented platform for them: most of the examples and cases belong to this in interviews, it has been mentioned 217 times in 15 interviews, it marks an average of 14-15 times per interview. This is a relevant result in view of the biggest social media platform with 1.26 billion users (source:http://www.theverge.com). The second indicator "digital identification tools" depicts self-surfing, other people's online cheeking, reflection for network impact. Facebook is checked quite often/regularly - daily - to be able to manage their upload, activity and influence and to monitor other people's activities joint with their media/online representation. Other routines of social media surveillances may operate on a weekly basis or even less often than that. Google self-surfing is not characteristic. Informants are wired in networks to various extents ranging from about 50 to 500 connections. They use smaller or bigger close groups or "inner circles" consisting of 2-10 associates. They manage and control their networks and self-representation via private and public groups and limited connections. They check their shared content impacts such as how many "likes" or comments to arrive for a post or a comment. For them the most regular tool of identification on the internet is the photo. Profile trafficking by way of social media platforms is usually constituted by means of photos, labels, videos and, sometimes, they add timelines. These are strong tools of the visual and emblematise Davies' conception of "display-identity": "online images can accrue cumulative meanings from their digital contexts $[(2007,561)$ see Figure 1$]$.

Behaviour and goals in digital networks as third indicator give a feedback for the second indicator. The identification process is one of the most frequented goals of social media and other online services usage. This process regularly activated while searching, (self)surfing or while looking for or after somebody. Searching is at the core of understanding or tracing others' digital identities and the way s/he monitors the digital identity of his/her own. Informants try to hold under control their online networks and the 
communication process of this. They suppose their social roles and their online representation to have been semi-visible and they know they can only partly manage this visibility. They avoid communication with reference to extremity and they have conversations some of which should and others should not be public. Their goal is just to check and control the online representation and network effects if necessary.

Figure 1: Mentions for identifying in corpus (frequency). $\mathrm{N}=157$

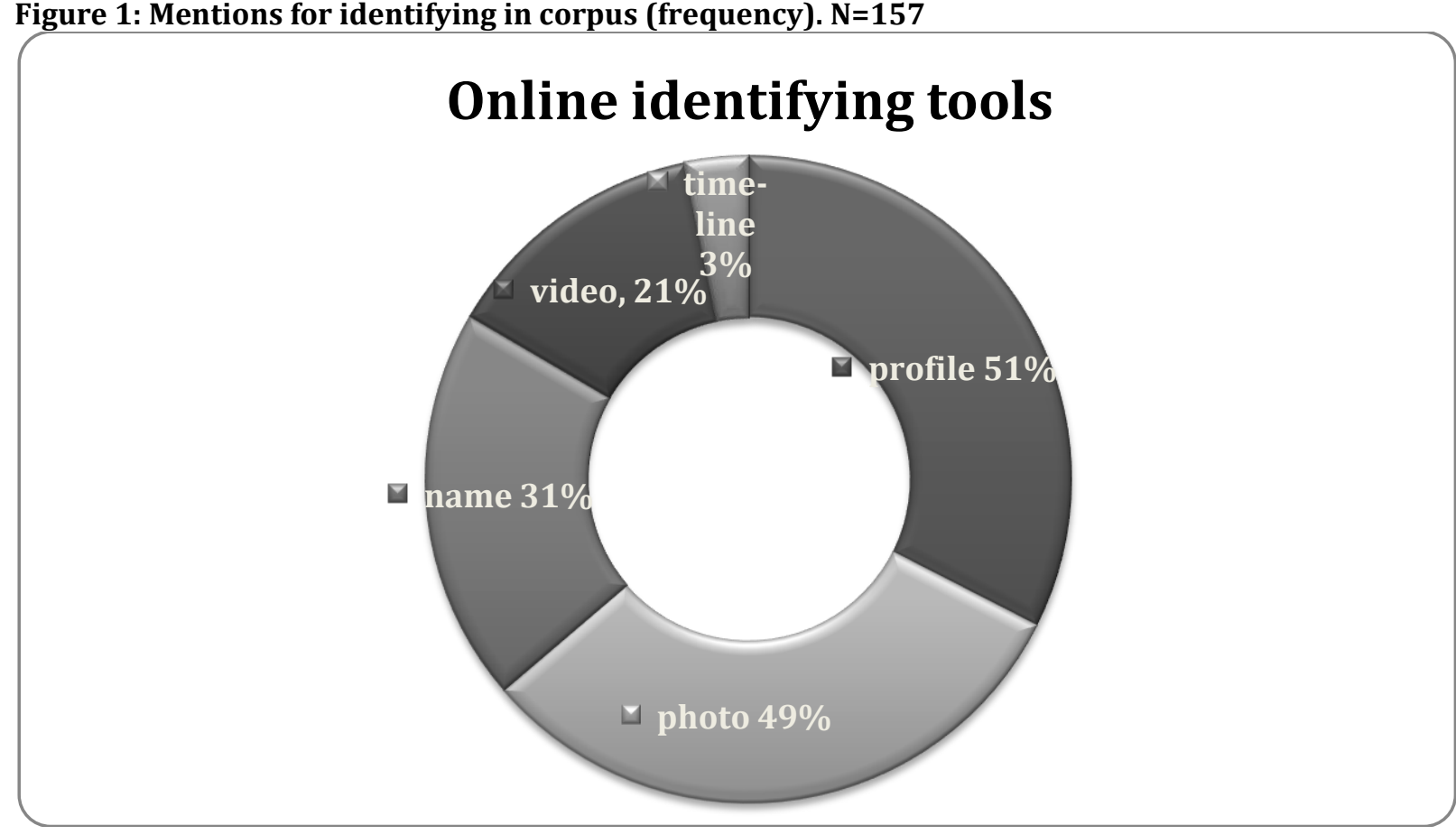

They would not spend too much time with this. They reflect negative or irrelevant contents with reference to themselves and they inform one another about extreme experiences such as digital identity theft. The total of our research focuses mainly on digital identity strategy. The fourth indicator is the most important one for further steps of the research that we have been planning. We assumed users' digital skills and knowledge with conscious strategy is over by the time their university studies are completed - before the first job in this segment. The interviews revealed that there was no coherent/holistic strategic approach available. Indeed, there are situations in which some users have a strategic approach, while others do not. We were interested in these strategic elements and we have finally formulated our assumptions relying on them. From this point of view strategies were divided into sections, and, on the one hand, we have examined the areas in which there has been a clear strategic approach available for users, and, on the other hand, those areas in which strategic approaches of any kind are only partially available or no approach is available at all. Half of the users have direct and successful strategies to manage digital footprints and the other half of the users has strategies that are limited to some of the segments of digital identity. The "observer" status in social media is their selfperception: our users have activity online but the main habit is observing other people's lives in their social networks; the picture/photo surfing for relevant impressions about people in observation. It was surprising that self-expression and creativity were not among the core concepts. On the other hand the control is a highlighted question for them: what can they do if something is happening and this means a negative impact for their online reputation. As one of the users warned:

"Whatever is on the internet it can be of an extremely devastating effect on people's lives. No one can stop them, because pretty much everyone on the internet might post whatever s/he wants".

They agree in principle that reputation is rather vulnerable, but they do not worry about data surveillance. They try to handle it with stronger passwords and fake registered identities, sometimes they use nicknames. This deception is accepted in some cases in internet usage (Birchmeier et al., 2005; Gonzales \& Hancock, 2008). Risk, trust and behavioural intentions are related closely in online identification (Backhouse \& 
Halperin, 2012). Informants' points of decisions come from attitudes of observation and from the need for control. Their points of decisions depend on platform settings and network impacts. The strongest motivation is to save their privacy. They recognise "other faces online" and this provides an insight into other online subjects' hobbies, networks, interests and other features that are not visible offline. But they want to preserve some things just for offline "live" situations and for close groups. They respect and follow the "best practice" online representation with non-extreme display-identity. It means they do not make communication noise for other people. The moral point of view was also very strong in interviews: they do not do anything online that you do not want to do with them. However they would warn and inform others without fail as an altruist habit. To sum up their decisions about digital identity and network activity correlate with questions of control, privacy, non-extreme online habit and morality. These are the main points of decisions and they focus on "what I do not want to do". Informants spend time with observation to define these "NO" points. The "what I can do" is a less strong point for them: everybody lives online, and they can handle the digital arena. In accordance with their status - they are students - they live in the simple flow of a non-vulnerable lifestyle. Here comes a nice view by one of the informants:

"Ifyou see something about me, no one cares. Well, probably my mum does."

Informants' visibility is mainly provided by points of control. If they can save their privacy and they can avoid online-public conflicts because of moral points of decision that is all to manage with reference to their digital identities. They interpret their points of decisions just like their contemporaries. Informants mentioned frustration about family and about relationship online communication. They have more questions about it like how and when they can begin or end their relationship in online network visibility, which family photos were not accepted - and so on. Finally the shared points of decisions and the variables of goals and preferences generate most of the questions for users in online visibility. At last the last research indicator was the strategy shift consciously prior to employment. As we mentioned they respect and follow the "best practice" online representation. Informants search and fix people who could be role models for them. This is the point where their interest and future plan meet. They follow mainly professional experts and tutors who give them best practice patterns for online self-representation and professional life together. Informants spend time to look for and observe well-known/professional people. It confirms their career goals with online support and strengthens career motivation parallel. We have to admit that we were surprised to see the lack of interest in their online reputation management. While they are, on the one hand, preparing their prospective professional careers, they do, on the other hand, not have straightforward online footprint management strategies. Informants do not build a professional profile or professional network now to prepare their next digital identity before their first job. They only have some ideas of the future: they would like to change their profile from "student" to that of a "professional" assuming less activity in digital context. They mentioned two reasons to wait with building an online self-brand. The first one was their lack of professional experience. They do not use the LinkedIn professional social network in lack of job experience and that of valid professional networking. They are waiting for getting the first job with logging in at/on these platforms. Furthermore, they do not know exactly what kind of job or company profile will determine their professional status. Finally this is a last minute for them before they begin to build their professional carrier with a digital profile, but it does not take frameworks for them to define themselves in online professional networks. Some of the participants have self-edited blogs and other forms of experience to manage online contents. They forecast advantages of these for prospective self-brand communication.

\section{Conclusion and further objectives}

Research results indicate the relevance of the topic and the importance of studying digital identity strategy. Our research has marked that digital identity phenomena define social roles/online strategies and representations on digital platforms and in social media. Members of the qualitative research segment have strategies to manage their digital footprints and to organise in forms of online visibility and to constitute networks' impact. This strategy is based on "NO" points of decisions: it depends on which activities are irrelevant for participants because of network effects and on account of morality. The major points of decision constitute privacy settings and they are not preparing their professional digital footprints in social media. We were surprised because of the lack of interest in online reputation: while they are, on the one hand, preparing their prospective professional careers and they follow best practices with the assistance of professional experts, they do, on the other hand, not have straightforward online footprint management 
strategies. The reason is simple: they live in other networks now and they have no experience to build their self-brand with. They say they shall simply redesign their present account if they get the first job. There are few exceptions in spite of personal history (see content management background.). But they do not feel - just with internship programs or other minor forms of experience - their background strong enough for this. On a conceptual level this paper hopefully contributes to a better understanding of the phenomenon of digital identity. At this important stage we are preparing a comparative qualitative research in further segments and cultures, and after that we begin a quantitative research with a bigger sample according to our hybrid research design. We want to keep personal/social/public identity strategies in mind via this qualitative research to complete it with basic concepts of digital identity in the future. "ICTs are changing some of the most fundamental concepts: the 'electronic version' of real identity, a form of social subjects' digital presence manifested by Internet addresses, data, and network connections. Online identity should not be considered as another re-incarnation of a 'real' identity, but as a specific kind of identity with an independent and ever increasing importance." (Resnyansky, 2010).

Acknowledgement: I am grateful to Budapest Business School where I was a senior research fellow when I started to work on this paper. Thank you for Mathias Corvinus Collegium to contact generation Y. The academic framework of BBS Research Centre enabled me to do research and publishers who have contributed to this paper.

\section{References}

Aaltonen, A., Huuskonen, P. \& Lehikoinen, J. (2005). Context awareness perspectives for mobile personal media. Information Systems Management, 22(4), 43-55.

Adler, R. B., Rosenfeld, L. B. \& Proctor, R. F. (2010). Interplay: The process of interpersonal communication (11th Ed.) New York: Oxford.

Allwood, C. M. \& Selart, M. (2001). Decision Making: Social and Creative Dimensions. Kluwer: Amsterdam.

Backhouse, J. \& Halperin, R. (2012). Trust, risk and eID: Exploring public perceptions of digital identity systems. First Monday, 17(4), 1-5.

Bauer, M. W. \& Gaskell, G. (2007). Qualitative Researching with Text, Image and Sound. London: Sage.

Blanchard, A. \& Markus, L. (2007). Technology and community behavior in online environments, presented at the 3rd International Conference on Communities and Technologies, Michigan State University, Lansing, MI, June 28-30.

Birchmeier, Z., Joinson A. N. \& Dietz-Uhler, B. (2005). Storming and forming a normative response to a deception revealed online. Computers in Human Behavior, 23(1), 108-121.

Buss, A. \& Strauss, N. (2009). Online Communities Handbook. Berkeley: New Riders.

Davies, J. (2007). Display, Identity and the Everyday: Self-presentation through online image sharing. Discourse: Studies in the Cultural Politics of Education, 28(4), 549-564.

Dellarocas, C. (2010). Online Reputation Systems: How to Design One That Does What You Need. Sloan Management Review, 51(3), 33-38.

Erikson, E. H. (1968). Identity: Youth and crisis. New York: Norton.

Gonzales, A. \& Hancock, J. T. (2008). Identity shift in computer-mediated environments. Media Psychology, $11(2), 167-85$.

Kennedy, G., Krause, K. L., Gray, K., Judd, T., Bennett, S., Maton K., Dalgarno, B. \& Bishop, A. (2006). Questioning the next generation: A collaborative project in Australian higher education. Proceedings of the 23rd annual ascilite conference: Who's learning? Whose technology? In. Markauskaite, L., Goodyear, P., \& Reimann, P. (Eds) Who's Learning?, Whose Technology?, Proceedings of the 23rd Annual Conference of the Australasian Society for Computers in Learning in Tertiary Education (pp. 413-417). Sydney, ASCILITE.

Mehdizadeh, S. (2010). Self-presentation 2.0: narcissism and self-esteem on Facebook. Cyber psychology. Behavior and Social Networking, 13, 1-8.

Resnyansky, L. (2010). Online identity as a semiotic phenomenon. In K. Michael (Ed) Proceedings of the 2010 IEEE International Symposium on Technology and Society: Social Implications of Emerging Technologies, 7-9 June 2010, University of Wollongong, New South Wales, Australia.

Schawbel, D. (2009). Me 2.0. New York: Kaplan. 
Shao, G. (2009). Understanding the appeal of user-generated media: A uses and gratification perspective. Internet Research: Electronic Networking Applications and Policy, 19(1), 7-25.

Tajfel, H. \& Turner, J. C. (1979).An integrative theory of inter-group conflict. In L.W. Austin \& S. Worchel (Eds.) The Social Psychology of Intergroup Relations. (pp. 321 - 333). Monterey, CA: Brooks-Cole.

Tajfel, H. \& Turner, J. C. (1986). The social identity theory of intergroup behavior. In S. Worchel\& L.W. Austin (Eds.) Psychology of Intergroup Relations (pp. 481 - 503). Chicago: Nelson-Hall. 